\title{
Implementation of lean thinking through A3 report in plastic injection company
}

\author{
Sartika Rini \\ Department of Industrial Engineering, Bina Nusantara University, Jakarta, Indonesia \\ sartika.rini@binus.ac.id
}

ARTICLE INFO

Keywords

Lean thinking;

A3 report;

Manufacturing industry.

\section{Article history}

Received:

November 5, 2020

Revised:

January 20, 2021

Accepted:

February 24, 2021

Available online:

February 24, 2021

\author{
ABSTRACT
}

Lean thinking, or lean production, which has long been introduced by Toyota, is a process improvement concept that is carried out by eliminating waste and focusing more on things that create values. Its emergence was inspired by the fact on the production floor, where only a small fraction of the total times and efforts contributed to creating added value to customers' final product. Lots of prior studies have shown various benefits of implementing lean production, especially in manufacturing industries. However, many companies still find difficulties trying to implement a lean approach for the first time. Furthermore, they do not have a clear and concise picture of each component of the lean approach they want to apply. This company is based on case study which has many rejected products so that it makes higher production cost. Therefore, this study proposed an implementation of lean thinking to reduce the number of rejected products through A3 report. This result show the defects can be reduced and the standard operational procedure has been developed.

\section{Introduction}

The increasing level of market competition in the manufacturing industries has made the implementation of lean thinking a robust approach to take (Herzog \& Tonchia, 2014). By definition, lean thinking is widely understood as a concept that leads to excellent performance and competitive advantage (Womack \& Jones, 1996). Another study of Thangarajoo (2015) defines lean thinking as an approach in a production system that is carried out to create value effectively and efficiently by focusing on consumers and the company's core competence. Furthermore, lean thinking is an approach that has been globally applied by company leaders in various operational areas to optimize operational performance and customer satisfaction (Howell, 1999; Waurzyniak, 2003; Holweg, 2007; and Nordin et al. 2010). Several reports and study (EEF Productivity Survey, 2001; IW/MPI Census of Manufacturers, 2007; Lila, 2012) consecutively point out that almost $50 \%$ of UK based companies, $70 \%$ of manufacturers in the USA, and $61.8 \%$ of respondents from a study of automotive manufacturers in the eastern region of Thailand has applied lean thinking in their companies.

Apart from those mentioned above, the high number of lean thinking implementation, especially in manufacturing industries, is due to the many benefits obtained from its application. Some of those advantages are increased process understanding, reduced inventory, less process 
waste, reduced lead-time, less rework, and financial savings (Melton, 2005). A recent survey from NIST (2003) of 40 companies that had adopted LM showed improvements in three areas such as operational improvements, administrative improvements, and strategic improvements. In order to gain all of the benefits offered by lean thinking, what the company needs to do, of course, is to start implementing it. Lean thinking starts with the customer and the definition of value (NIST, 2003). Therefore, since a manufacturing process is a vehicle to deliver value to a customer, lean thinking principles should be applicable to the whole process in every specific industry and even company. The efforts to eliminate waste as the key in lean thinking should be made in every stage of the process from upstream to downstream, consisting of the process deign and initial product development, compliance assurance, and the design to operate a completed facility (NIST, 2003). These elements or stages should be linked in a robust integrated system to implement truly lean thinking. However, numerous companies have struggled with integrating all of those various elements. The process of applying lean thinking is often carried out partially on each element so that a good integration does not go well. Thus this condition can trigger the failure in achieving the goals and benefits of implementing lean thinking.

According to the background, this study explores the process and the stages of implementing lean thinking in plastic injection company by utilizing the A3 report as its tool. Therefore, through this study, various parties who are having difficulties in implementing lean thinking can have an overview and guidance for future implementation.

\section{Literature Review}

A3 is an improvement process that applies lean thinking to problem-solving (Flinchbaugh, 2012). It is an approach to present a comprehensive yet organized report on a single-page. This tool is perceived as helpful in the early stages of preparations for implementing lean thinking to problemsolving. It seems to be because the building blocks contained in the A3 report are very simple and easy to understand. The A3 building blocks can be categorized to: (1) background, (2) current condition, (3) goals/targets, (4) analysis, (5) proposed countermeasures, (6) implementation plan and (7) follow-up (Saad et al., 2013). However, A3 is rather a way of thinking than a standard document format. Thus, the building block elements in the A3 report can be adjusted according to each company's needs and conditions.

A3 can solve various problems, from the simple and trivial ones to the complex like strategic problems by executives. It can be said that the $A 3$ report is suggested to be used when collaboration in thinking is required. An A3 report is also suggested to be utilized when any ideas need to be made more visible. Moreover, it is supposed to be used when there is a knowledge gap among individuals.

\section{Research Methodology}

This paper's research methodology consists of 2 phases: 1) Investigating lean thinking to problem-solving approach; 2) Developing A3 report template design 3) Implementing A3 report tools. The first phase was carried out using the literature review method, in which the results were contained in section 1 (introduction) and section 2 (literature review). The next phase, which is developing an $\mathrm{A} 3$ report template design, begins with a literature review process followed by 
adjustments to its needs and condition. The process of developing an A3 report template design is divided into two parts: 1) Identifying learning cycles; 2) Identifying A3 building blocks. This phase is written in section 3 (research methodology), while the last phase written in section 4 (result and discussion).

\subsection{Learning Cycles}

A study of Saad et al. (2013) have identified several learning cycles that might be used for the A3 thinking approach in product design. The following are the selected learning cycles:

- Plan-Do-Check-Act (PDCA)

- Look-Ask-Model-Discuss-Act (LAMDA)

- Define-Measure-Analyse-Improve-Control (DMAIC- Six Sigma)

- Identify-Design-Optimise-Verify (IDOV - Design for Six Sigma)

From the four learning cycles model above, one model will be selected to be used to develop the A3 report template design. The learning cycles selection process is carried out by determining and comparing several criteria, as shown in Table 1 which depicts the fulfilment of all criteria by the PDCA and LAMDA model. However, the author selects the PDCA model to be utilized in this study as it is well known among stakeholders.

Table 1. The criteria of the learning cycle for developing an A3 report

\begin{tabular}{|l|c|c|c|c|}
\hline \multirow{2}{*}{ Criteria } & \multicolumn{4}{c|}{ Learning Cycles } \\
\cline { 2 - 5 } & PDCA & LAMDA & DMAIC & IDOV \\
\hline 1. Used in Lean Process Development & $\mathrm{v}$ & $\mathrm{v}$ & & \\
\hline 2. Solve Problem & $\mathrm{v}$ & $\mathrm{v}$ & $\mathrm{v}$ & $\mathrm{v}$ \\
\hline 3. Provides Single Documentation & $\mathrm{v}$ & $\mathrm{v}$ & & \\
\hline 4. Used as a Communication Tool & $\mathrm{v}$ & $\mathrm{v}$ & & \\
\hline 5. Easy and Simple & $\mathrm{v}$ & $\mathrm{v}$ & & \\
\hline 6. Knowledge Sharing & $\mathrm{v}$ & $\mathrm{v}$ & & \\
\hline \multicolumn{1}{|c|}{ Total } & 6 & 6 & 1 & 1 \\
\hline
\end{tabular}

\subsection{A3 Building Blocks}

Further details of the learning cycles model that has been selected (PDCA) need to be made. Thus, a Forum Group Discussion (FGD) was carried out, and the result can be seen in figure 1. The plan-stage consists of problem identification, aim statement, understanding the current condition, grasping the situation, and setting targets. The do-stage consists of 3 building blocks such as target state matrix, gap analysis, and action plan. The check-stage is consist of one building block, namely counter measures. The action-stage is consist of improvement, standardization, and control and education. 


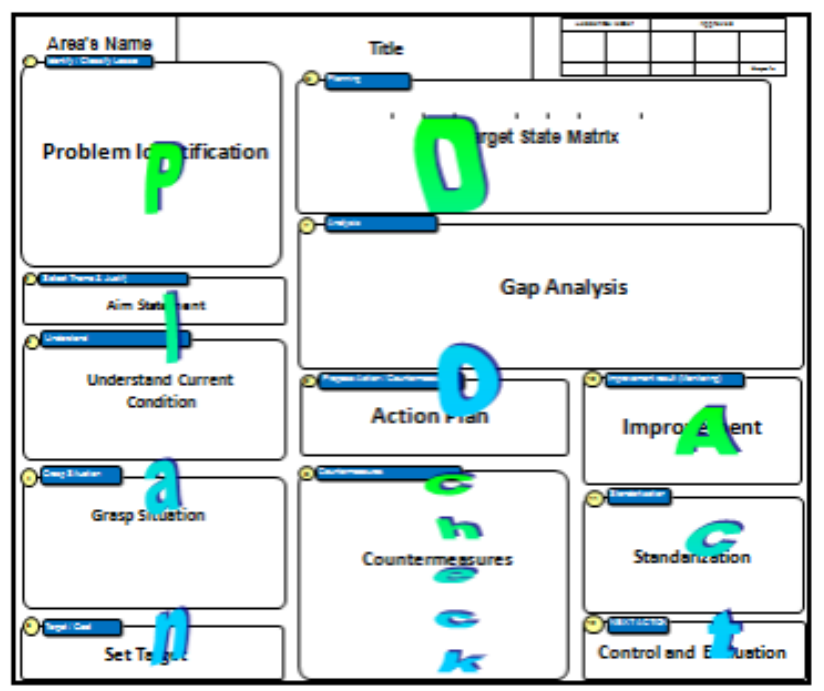

Figure 1. A3 report template design

\section{Results and Discussion}

This section elaborates the results and discussion. This research is based on a case study of a plastic injection company in Indonesia. The problems are there are many rejected products in labelling machine no. 6 . Therefore, this study proposed the implementation of lean thinking to reduce the number of rejected products through the $A 3$ report. Figure 2 presents a lean thinking implementation through the A3 report. The "Background" section captures how the problem relates to a labelling machine no. 6 that had peeled off from the particular product. The audience that's being considered here is middle-level managers that must dedicate resources to the effort and also be able to report to upper management. The "Current Condition" section explains that the current condition had two problems: label damage and label sleeve adhesion. Then, the "Goal" reduces the customer complain label peel off, improves quality, and increases productivity on labelling and sticker machine.

The "Root Cause" section summarises using the 5-Why's and Ishikawa (fishbone) diagram. It was revealed that the root cause of the tension of the finishing sticker was weak. Also, the body of the product was dusty, so the stickers could not appropriately be attached. The proposed "Countermeasures" section lists the areas that will add cleaner/swipe before and after stickers attached. The cleaner/swipe need to be changed every two weeks. Also, workers need to put on their gloves properly to make the product cleaner. Task leaders and due dates are also provided to keep the effort on track. Next, the "Effect Confirmation" section shows that the countermeasures have reduced the peel-off label from 7 to zero even it takes a few months of monitoring. Finally, the "Follow-up Actions" section continues to ensure all action plan. 


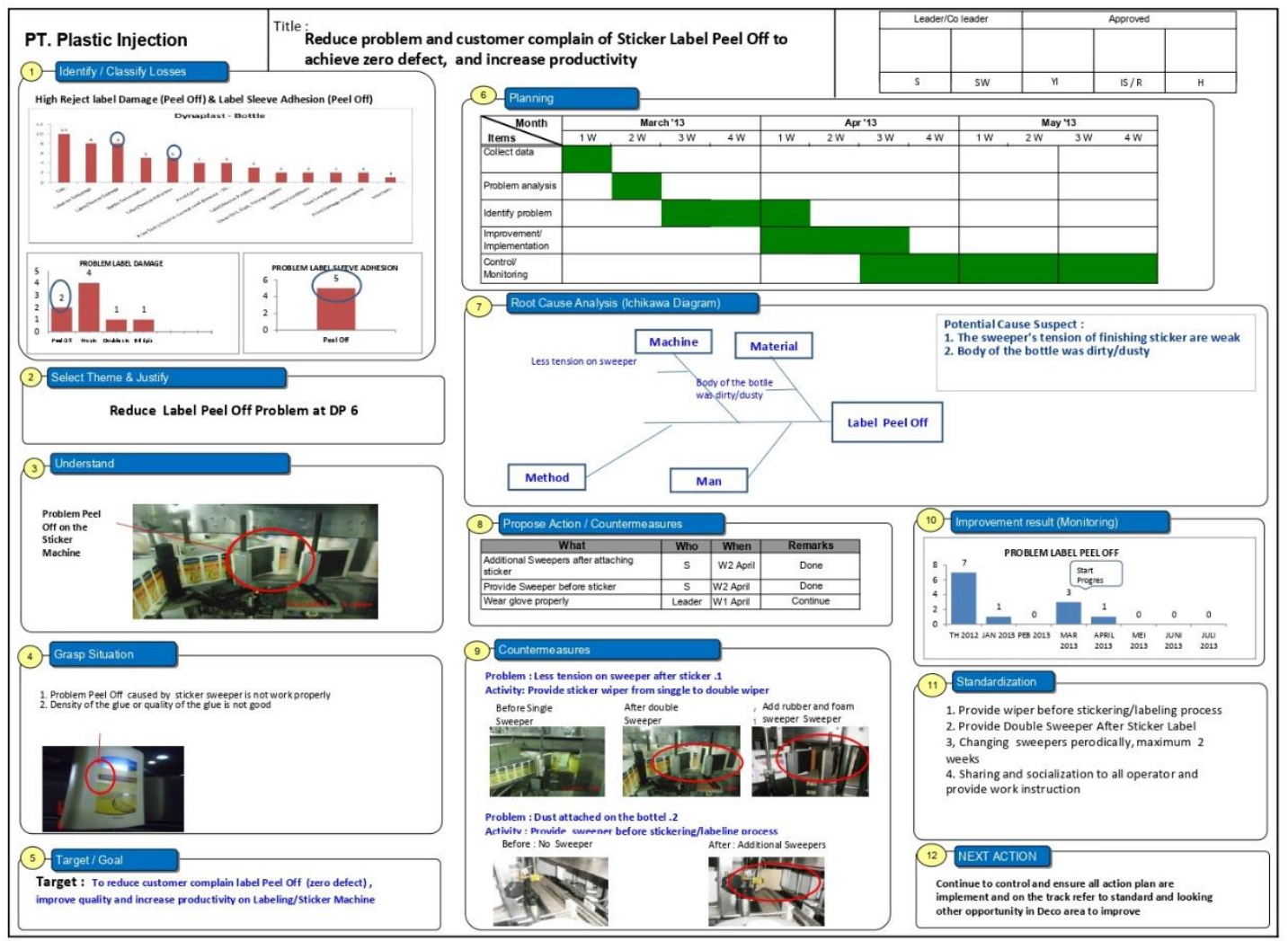

Figure 2. Implementation lean thinking through A3 report

\section{Conclusion}

A business could encourage their workers to improve their workplace by eliminating waste which is the core of lean thinking. The process of eliminating waste can be done through PDCA which is the basis of the A3 report. PDCA is a gradual process that has been an accumulation from many decades of effort. Much was learned from the valid failures which arose, but only after the root causes were identified and understood. The company's performance metrics are rising again. The future looks very strong utilizing both PDCA and their simple lean management and leadership learning tool called the A3 within their organization, business practices and culture. The company's PDCA culture develops in a gradual process that involves individuals thinking outside of themselves. Due to the analysis derived from this paper, the authors recommend that a company avoid having employees in problem-solving situations jump to conclusions to provide apparent solutions. These "sure" solutions typically have a component of emotional attachment, which may not address the real issue. The organizational culture must pull from other team members who can contribute to a more profound solution. Missing the optimum opportunities squelches performance opportunities which only accumulate throughout the year. Like Toyota, organizations with the A3/PDCA mentality should drive lean management and leadership thought processes, allowing larger chunks of improvement to be reaped. Through training and mentoring, 
more employees should become champions of improvement, thinking objectively, and be free of ego.

\section{References}

EEF Productivity Survey. (2001). Catching up with Uncle Sam: The EEF final report on US and UK manufacturing productivity

Flinchbaugh, J. (2012). A3 problem solving: Applying lean thinking. Lean Learning Center.

Herzog, N. V., \& Tonchia, S. (2014). An instrument for measuring the degree of lean implementation in manufacturing. Strojniški vestnik-Journal of Mechanical Engineering, 60(12), 797-803.

Howell, G. A. (1999). What is lean construction-1999. In Proceedings IGLC, 7, 1.

Holweg, M. (2007). The genealogy of lean production. Journal of operations management, 25(2), 420-437.

IW/MPI Census of Manufacturers (2007) Measuring continues improvement programs

Lila, B. (2012). A survey on implementation of the lean manufacturing in automotive manufacturers in the eastern region of Thailand. In Proceedings of the 2nd International Conference on Industrial Technology and Management (ICITM), 43-48.

Melton, T. (2005). The benefits of lean manufacturing: what lean thinking has to offer the process industries. Chemical engineering research and design, 83(6), 662-673.

NIST, 2003. Utah Manufacturing Extension Partnership, Manufacturing Extension Partnership, National Institute of Standards and Technology, Gaithersburg, MD.

Nordin, N., Deros, B. M., \& Abd Wahab, D. (2010). A survey on lean manufacturing implementation in Malaysian automotive industry. International Journal of Innovation, Management and Technology, 1(4), 374.

Saad, N. M., Al-Ashaab, A., Shehab, E., \& Maksimovic, M. (2013). A3 thinking approach to support problem solving in lean product and process development. In Concurrent Engineering Approaches for Sustainable Product Development in a Multi-Disciplinary Environment, 871882. Springer, London.

Thangarajoo, Y., \& Smith, A. (2015). Lean thinking: An overview. Industrial Engineering \& Management,[e-journal], 4(2), 1000159.

Waurzyniak, P. (2003). Going lean at Baxter. Manufacturing Engineering, 130(5), 89-89.

Womack, J.P., \& Jones, D.T. (1996). Lean Thinking: Banish Waste and Create Wealth in Your Corporation, Simon \& Schuster, New York. 